Resumen por el autor, Henri C. van der Heyde.

Sobre la respiración del Dytiscus marginalis L.

El autor estudia el mecanismo de la respiración de Dytiscus marginalis mediante un nuevo aparato. Cuando el animal respira en un espacio cerrado por una gota de petróleo pueden observarse movimientos en dicha gota. El primer movimiento observable parece ser una expiración, cuyo hecho está en abierta contradicción con las afirmaciones previas de otros autores. El autor propone una teoría para explicar este hecho tratando de verificarla de diversos modos. Mediantc un nuevo aparato estudia el aire después de haber permitido respirar al animal en él durante algun tiempo. El hecho señalado por Ege y Kreuger de que el $\mathrm{O}_{2}$ acumulado en la cámara aérea es consumido durante la permanencia del animal debajo del agua has sido comprobado por el autor. La importancia biológica de la difusión del oxígeno en la cámara aérea es objeto de discusión bajo el punto de vista físico-quimico y el autor la considera de un modo matemático. Por último, la importancia relativa de los gases del agua y del aire para el comportamiento del animal son también objeto de estudio. Parece que aún cuando el animal se ha emancipado hasta cierto punto del medio ambiente originario depende mucho más del aire que del contenido gaseoso del agua.

Translation by José F. Nonidez

Cornell Medical College, New York 


\title{
ON THE RESPIRATION OF DYTISCUS MARGINALIS L.
}

\author{
H. C. VAN DER HEYDE \\ Physiological Laboratory of the Free Universily in Amsterdam, Holland \\ THREE FIGURFS
}

For a comparative physiologist fresh water is the best medium from which to gather his material. It is, as Professor Jordan ${ }^{1}$ pointed out, very poor with regard to its more highly organized primitive forms. Nearly all representatives of those groups which are called 'high' in the scale of phylogenesis of the morphologists and systematists, especially the insects, prove by their structure that doubtlessly they originally inhabited the land. As the structure of an organism is determined on one side by its phylogenesis, but on the other hand by the claims of 'Milieu' and 'Umwelt,' we may expect that this change of surroundings has caused certain morphological and physiological peculiarities which we are accustomed to call phenomena of 'adaptation' or better perhaps of 'being adapted.' Without trying to give an explanation of these phenomena, it is the task of the comparative physiologist to state them and to study them with all applicable methods. Then it will be of special interest to see how far a certain species has emancipated itself from its original environment and how the same problem has been solved in quite a different way in related groups of animals, when we compare, for instance, Dytiscus and Hydrophilus with regard to their respiration in the groups of the Adephaga and the Polyphaga.

The respiration of Dytiscus has already been studied by numerous investigators, though mostly from the morphological standpoint. In this paper I shall mention some experiments which seem to throw a new light on the whole problem.

1 Prof. Dr. H. J. Jordan. Het leven der dieren in het zoete water. Utrecht. Oosthoek, 1918. 
The mechanism of their respiration was already known to Swammerdam; he also knew that breathing in Dytiscus is entirely different from that in Hydrophilus. The old naturalist Frisch ${ }^{2}$ had not seen it, and in observing Dytiscus only was led to generalize. Nitzsch, ${ }^{3}$ a more careful observer, corrected this and emphasized the difference between the two species.

It is not my intention to give a complete history of our knowledge of this problem. Such review should be absolutely complete or not be given at all. Moreover, the interested reader can find a complete though not wholly impartial summary of the older investigations (till about 1912) by Babak in Winterstein's Handbuch der vergleichenden Physiologie, I. Bd., 2 Hälfte, p. 452 seq., while most of the more recent studies have been mentioned in Ege's paper. ${ }^{4}$

The problem to be solved here has many sides. In the first place, the animal must be able to stay for a certain time in the water. In consequence of its type of organization, however, it is not entirely independent of the atmospheric air. Intermittently it must come to the surface to breathe, and now the problem has to be solved how to penetrate the surface layer. This problem has been solved in an entirely different way by Dytiscus and Hydrophilus.

Dytiscus breathes with the edge of its abdomen. By complicated movements of this abdomen which have been studied in great detail by du Bois-Reymond ${ }^{5}$ and Plateau ${ }^{6}$ and in which the muscles of the 'Genitalkapsel' play an important rôle-these

${ }^{2} \mathrm{~J}$. L. Frisch. Beschreibung von allerley Insekten in Teutschland. 2 Teile. Berlin, 1721.

${ }^{3}$ Ch. L. Nitzsch. Ueber das Athmen der Hydrophiliden. Arch. f. Phys. Reil und Autenrieth., Bd. 10, S. 440, 1811.

${ }^{4}$ Rich. Ege. On the respiratory function of the airstores carried by some aquatic insects (Corixidae, Dytiscidae and Notonecta). Zeitschr. f. Allg. Physiol., Bd. 17, S. 81, 1918.

${ }^{5}$ R. du Bois-Reymond. Ueber die Atmung von Dytiseus marginalis. Verhandl. der deutschen Physiol. Ges. Arch. f. Phys., 1898, S. 378.

- F. Plateau. Recherches expérimentales sur les mouvements respiratoires des insectes. Bull. Acad. Roy. Belg., T. 3, p. 727, 1882. 
muscles have for this reason been called accessory respiratory muscles-a cleft is formed between the edge of the abdomen and the two elytra. In that way the large space between the back of the animal and these elytra communicates freely with the atmospheric air. The edge of the abdomen is fatty, so that the water is prevented from coming into the dorsal space. In the opening itself we see a number of stiff hairs which probably have the purpose of keeping out dust particles and on the other hand prevent the air from escaping after the animal has dived into the water. Corresponding to this abdominal breathing, the whole bunch of stigmata has been moved backward. Without the aid of a lens two very large stigmata can be seen at the edge of the abdomen while the animal is breathing; moreover, all the other stigmata have moved in the same direction. Numerous anatomical details are given by Willy Alt. ${ }^{7}$

In connection with this brief description of the breathing process I wish to state that I am still in doubt whether the opening of the abdominal cleft occurs actively or simply in consequence of capillary forces as, for instance, the 'hair-crests' of Notonecta do. I base this doubt on the following observation:

In order to determine the consumption of oxygen of the animals in the water, I put two beetles into a beaker and covered the water with a layer of paraffin oil. After some time the beetles moved the edge of their abdomen towards the limiting layer apparently with the purpose of breathing. It appeared that they were not able to keep the cleft closed, though they had not yet reached the air. In that way the abdominal space was filled in less than no time with the oil, and the animals were completely motionless after a quarter of an hour. In order to keep them alive, I brought them back into the fresh air, but in less than two hours they died. When we take into consideration that the animals can live for much longer than an hour in the water without reaching the surface, we cannot explain this result by lack of oxygen.

${ }^{7}$ Willy Alt. Ueber das respirationssystem von Dytiscus marginalis L. Zeitschr. f. wissensch. Zool., Bd. 99, S. 357, 1912. Auch Zool. Anz.. Bd. 34. S. 793, 1909. 
The method of respiration of Hydrophilus is entirely different; it is, however, not my purpose to enter into details with regard to this species in the present paper.

Above all, it seemed desirable to me to study the breathing mechanism on the intact animal. Curves such as have been traced by $\mathrm{Babak}^{8}$ may give rise to the objection that they do

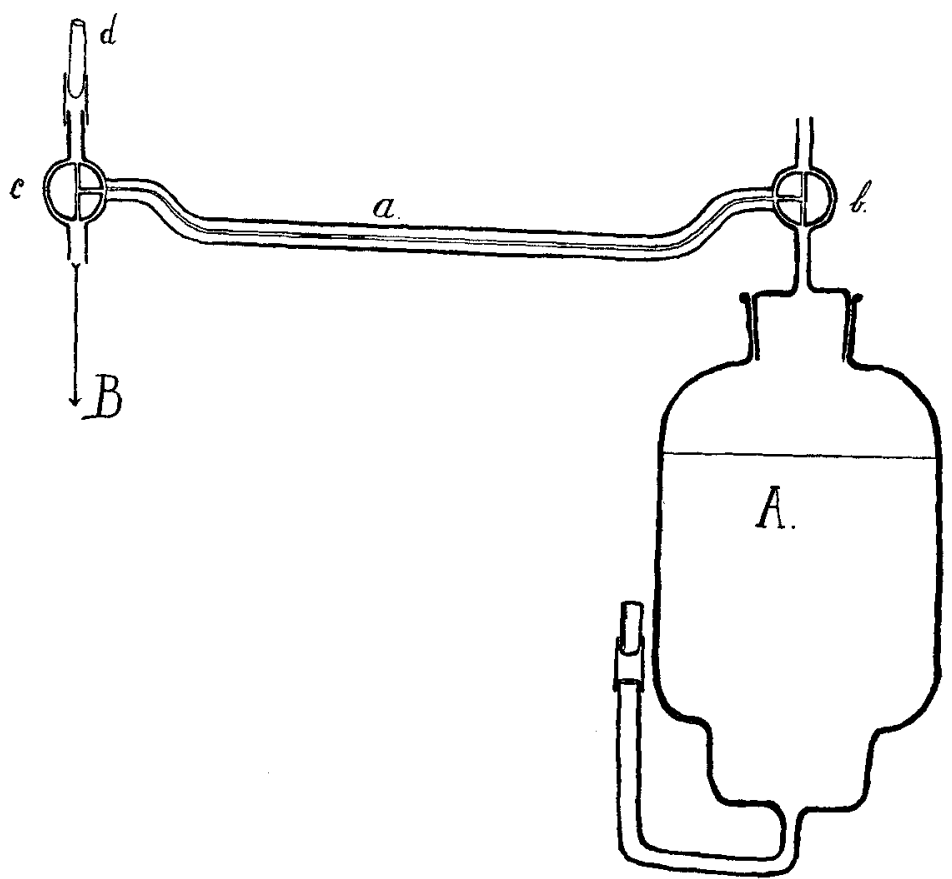

Fig. 1. Apparatus for the registration of the respiratory movements of Dytiscus.

not represent the normal breathing mechanism of the beetle. This author made an opening in the elytra, fixed the animal with pins, and fastened a hooklet in its back. In that way he could register the movements of the back on a kymograph. The great difficulty however, which must be surmounted is the fact that the whole respiratory apparatus is completely covered by the large elytra. On the suggestion of Professor Buytendyk, I finally used the apparatus of figure 1.

${ }^{8}$ Prof. Dr. Edw. Babak. Mitw. stud. med. J. Hepner. Untersuchungen über die Atemzentrentätigkeit. I. Ueber die Physiologie der Atemzentrentätigkeit von Dytiscus mit Bemerkungen über die Ventilation des Tracheensystems. Pflüger's Arch., Bd. 147, S. 349, 1912. 
In the vessel $A$ I put the beetle in a certain quantity of water. The vessel $B$ has the purpose of compensating occasional differences in temperature and vapor pressure. Both vessels contain about the same amount of water. In the capillary tube, $a$, a drop of petroleum moves up and down. Petroleum is to be preferred to water in consequence of its smaller friction coefficient. The utmost care should be taken to keep the capillary tube absolutely dry; the sensitiveness of the whole apparatus is lost as soon as any water penetrates into this tube. In $b$ and $c$ we have a three-way cock, the purpose of which can be easily understood from the figure. I must still mention, in the first place, the glass stopper, $d$, with which we can bring the droplet to any desired spot when the apparatus is ready for use; in the second place, the tube $e$ through which the water can leave when the apparatus is filled from above with some gas, e.g., $\mathrm{H}_{2}$ or $\mathrm{CO}_{2}$. In ordinary circumstances they are closed with a glass stopper. Care must be taken to keep the tube $a$ absolutely horizontal; finally, the apparatus was put in water to keep the temperature as constant as possible.

Let us now describe systematically the movements which the droplet makes in the different periods of the breathing process.

A. As soon as the animal reaches the surface and opens its abdominal cleft, the droplet first does not move. Whatever may take place during this period, it is clear that in this way an occasion for an exchange of gases between the dorsal space and the atmospheric air is given.

B. A short time after this the droplet moves first slowly, then more quickly, sometimes intermittently and with pulsations in the direction of the distal end of the tube. Obviously, the air is expelled in some way either from the dorsal space or from the tracheae. The first phase of the breathing process is thus an expiration, not an inspiration, as Babak (l.c., p. 350) and almost all other investigators postulate. Details will be given later on.

C. Almost always the animal dives immediately after this. Sometimes I could observe a recession of the droplet before the animal dived; the distance covered, however, in these cases was never more than about one-tenth of the distance traversed during the expiration. 
After the animal has dived we can observe the following movements of the droplet:

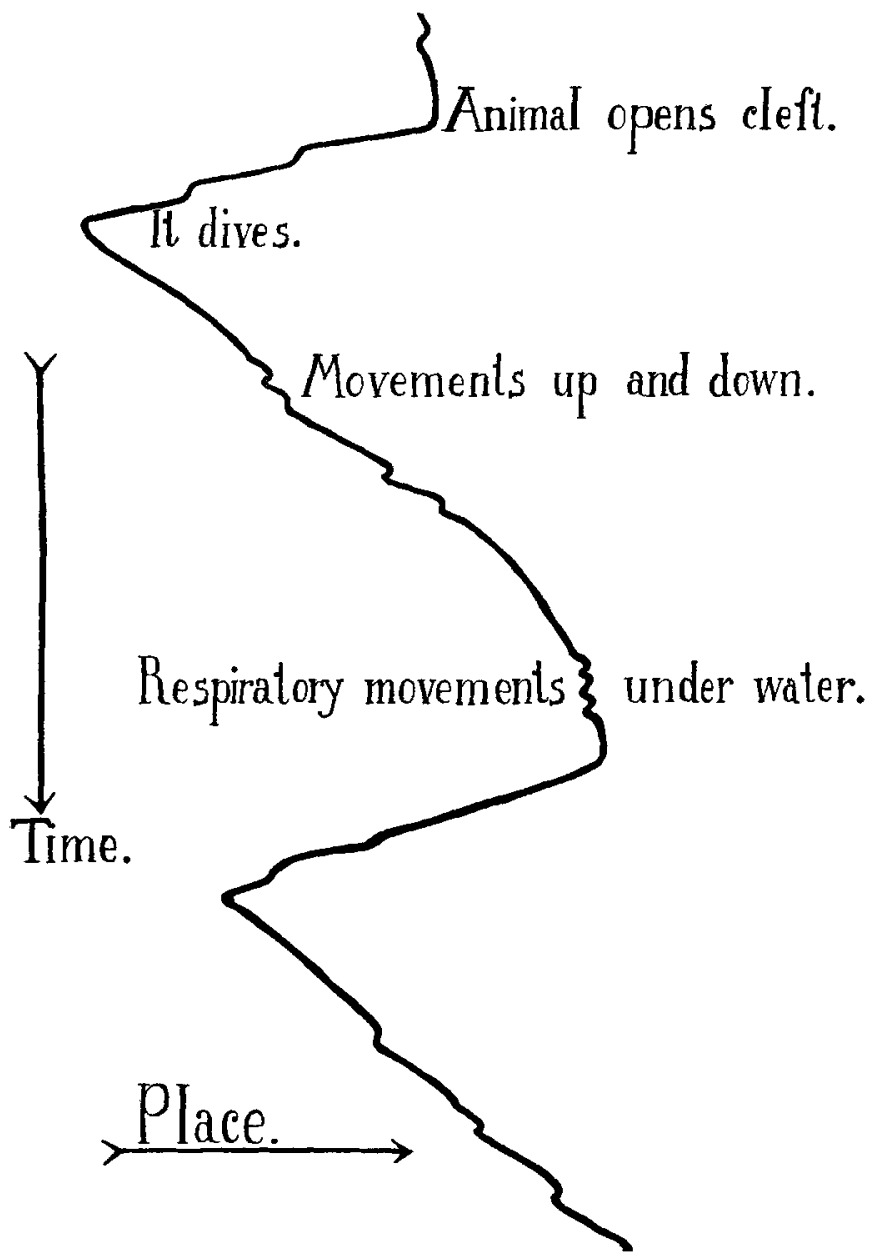

Fig. 2 Schematic representation of the movements of the droplet

D. In the first place, a regular retrogression of the droplet at a slower rate, but over a greater distance than was covered during the expiration. When the animal stays under water for a long time, the droplet scarcely shows any more movements. 
E. In the second place one can regularly observe very distinct hydrostatic movements. When the animal moves up and down in the bottle the air in the reservoir is alternately expanded and compressed. The extreme sensitiveness of the apparatus is shown by the fact that even these minute changes in volume can be read in the capillary tube. This gives, in the second place, a good test as to whether or not the apparatus is working all right in a certain series of experiments. Sometimes these movements do not show because the cleft is completely closed.

F. Finally, the definite proof can in this way be given that the animal breathes under water. This fact has been denied by several authors. Immediately after diving the animal is usually very motile. After some time, however, it comes to rest and may sit quietly at the bottom of the vessel for a while. Then one can observe several times a very distinct moving up and down of the droplet: in the meantime the gas-bubble in the cleft of the abdomen makes synchronous movements. The latter movements have already been observed by some authors, while others did not seem to realize their importance.

A diagrammatic representation of the whole process is tried in figure 2. The movements of the droplet are supposed to be projected on a vertically moving plane. In that way the ordinate gives the time, while from the abscissa one can read the location of the droplet at every moment.

We must now try to give an adequate explanation of these facts, and in doing so we must keep in mind the following considerations:

1. It has been shown by Ege that the oxygen of the reservoir is consumed during the animal's stay in the water. I could prove the exactness of this statement by the following analyses, which have been made with Krogh's apparatus for micro-gas analysis: ${ }^{9}$

A Aug. Krogh. On micro-analysis of gases. Scand. Arch. f. Physiol., Bd. $20,1908$. 
TABLE 1

\begin{tabular}{|c|c|c|c|}
\hline EXPERTMENT & $\begin{array}{c}\text { LENGTH OF } \\
\text { BUBBLEE }\end{array}$ & $\int_{\text {TURE }}^{\text {TEMPERA- }}$ & RESULT \\
\hline 1. Dytiscus, immediately after diving I press & 15.35 & $15.3^{\circ}$ & $0.65 \% \mathrm{CO}_{2}$ \\
\hline with my fingers a little air-bubble out of the & 15.25 & $15.5^{\circ}$ & $14.01 \% \quad \mathrm{O}_{2}$ \\
\hline $\begin{array}{l}\text { air-store; this bubble is immediately brought } \\
\text { into the apparatus and analyzed }\end{array}$ & 13.10 & $15.7^{\circ}$ & $85.34 \%$ \\
\hline \multirow[t]{3}{*}{ 2. The same, somewhat later } & 13.90 & $16.2^{\circ}$ & $0.72 \% \mathrm{CO}_{2}$ \\
\hline & 13.80 & $16.5^{\circ}$ & $12.81 \% \quad \mathrm{O}_{2}$ \\
\hline & 12.02 & $16.6^{\circ}$ & $86.47 \% \quad \mathrm{~N}_{2}$ \\
\hline \multirow{3}{*}{$\begin{array}{l}\text { 3. The animal is prevented from coming up for } \\
\text { some time by being shut in an inverted beaker. } \\
\text { After this analysis as before }\end{array}$} & 15.49 & $16.3^{\circ}$ & $0.64 \% \mathrm{CO}_{2}$ \\
\hline & 15.39 & $16.5^{\circ}$ & $3.05 \% \quad \mathrm{O}_{2}$ \\
\hline & 14.92 & $16.7^{\circ}$ & $96.31 \% \quad \mathrm{~N}_{2}$ \\
\hline
\end{tabular}

Analogous results have been obtained by Elsa Kreuger ${ }^{10}$ in a series of very careful experiments. This author studied, moreover, the rate of oxygen consumption, and could show that after a very rapid decrease in oxygen content in the beginning a kind of equilibrium is reached after a while between the tracheal air and the air of the reservoir, so that after that the curve proceeds much less steeply.

2. The animal really expires when it opens its breathing cleft at the surface. I could prove this fact which had already been made very probable by the movements of the droplet in the apparatus of figure 1 in using the following little apparatus, not previously described (fig. 3). It simply consists of a beaker covered by a flat cork. A space, $A$, has been made in the center of the cork ${ }^{11}$ in which a bubble of air can be brought through the pipette, $B .{ }^{12}$ The animal is allowed to breathe into this bubble after an equilibrium is practically established between the

${ }^{10}$ Elsa Kreuger. Ueber die Bedeutung des Elythralraumes bei Dytiscus. Lund Universites Årsskrift. N. F., Bd. 10, No. 13, 1915. Kongl. Fysiografiska Sällskapets Handlingar. N. F., Bd. 25, No. 13.

11 The air is kept in a hollow metal platelet, which is fixed to the cork by means of screws while the spaces above it were filled up with plasticine.

${ }^{12}$ For this reason the cork must not fit too tightly in the beaker so as to allow the water to escape at the rim. 
bubble and the water, ${ }^{13}$ and after a sample has been taken of the air with one of the pipettes, $C, D$, and $E$. These pipettes are built exactly like the ones described by Krogh. Care should be taken not to make them too long. After breathing, another portion is taken, and quickly the analysis is made, first of the third one, because the air is not in equilibrium with the water, afterwards of the control portion.

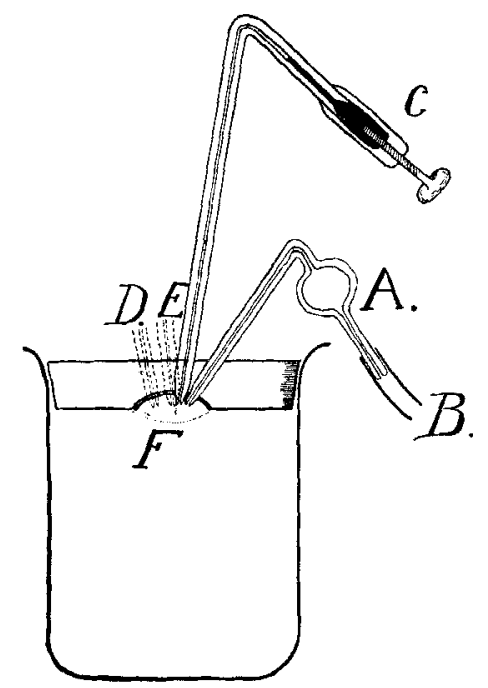

Fig. 3. Apparatus for the study of the expired air of Dytiscus. By moving a water-filled funnel connected with $B$ upwards, the air of the bubble $A$ is pressed into the space $F$, whereas the superfluous water escapes at the rim. The animal is allowed to breathe in the space $F$. With the pipettes $C, D$, and $E$ ( $D$ and $E$ have been indicated with a broken line, as they do not lie in the plane of the picture) we can at every movement get a sample of the air.

With this little apparatus I obtained the following results with regard to the composition of the air before and after breathing (the analysis has again been made with Krogh's micro-gas analysis apparatus):

13 It is very easy to prevent the animal from breathing for a while by shaking the beaker at the very moment when it intends to open its cleft for this purpose. 
TABLE 2

\begin{tabular}{|c|c|c|c|c|c|c|}
\hline \multirow{2}{*}{ EXPERIMENT } & \multicolumn{3}{|c|}{ BEFORE BREATHING } & \multicolumn{3}{|c|}{ AFTER BREATHING } \\
\hline & $\begin{array}{c}\text { Length of } \\
\text { bubble }\end{array}$ & $\underset{\text { Ture }}{\text { Tempera- }}$ & Result & $\begin{array}{l}\text { Length of } \\
\text { bubble }\end{array}$ & Tempera- & Result \\
\hline \multirow[t]{3}{*}{1} & 14.33 & $23.0^{\circ}$ & $0.21 \% \mathrm{CO}_{2}$ & 14.07 & $21.0^{\circ}$ & $1.07 \% \mathrm{CO}_{2}$ \\
\hline & 14.30 & $23.0^{\circ}$ & $20.24 \% \quad \mathrm{O}_{2}$ & 13.92 & $21.7^{\circ}$ & $13.07 \% \quad \mathrm{O}_{2}$ \\
\hline & 11.40 & $23.0^{\circ}$ & $79.55 \% \quad \mathrm{~N}_{2}$ & 12.08 & $22.0^{\circ}$ & $85.86 \% \quad \mathrm{~N}_{2}$ \\
\hline \multirow[t]{3}{*}{2} & 14.90 & $24.8^{\circ}$ & $0.14 \% \mathrm{CO}_{2}$ & 17.27 & $23.1^{\circ}$ & $1.63 \% \mathrm{CO}_{2}$ \\
\hline & 14.88 & $24.9^{\circ}$ & $21.21 \% \quad \mathrm{O}_{2}$ & 16.99 & $23.8^{\circ}$ & $15.29 \% \quad \mathrm{O}_{2}$ \\
\hline & 11.72 & $25.0^{\circ}$ & $78.65 \% \quad \mathrm{~N}_{2}$ & 14.35 & $24.5^{\circ}$ & $83.08 \% \quad \mathrm{~N}_{2}$ \\
\hline
\end{tabular}

These figures show once more: 1) that the animal expires as soon as it comes to the surface; 2) that the air-store at the end of the period during which the animal remains in the water contains much nitrogen, little oxygen, and less carbon dioxide than one would expect.

3 . In insects, contrary to what we find in vertebrates, expiration takes place actively as, according to Ege, Brocher ${ }^{14}$ strongly emphasizes.

4. Dytiscus is able to obtain some oxygen through diffusion from the water. What this means and in how far this oxygen intake has a biological importance will be discussed later on. Here I simply describe the following experiment.

One beetle was put into a beaker. In order to avoid as much as possible the diffusion of oxygen from the air into the water, I covered the surface with a floating cork with a little hole in the center for breathing (paraffin oil cannot be used, as stated previously). Moreover, the beaker was covered by a glass plate.

Before and after the experiment the oxygen content of the water was determined by the method of Winkler. ${ }^{15}$

Experiment $A$. Animal in the water during $2 \frac{1}{2}$ hours. Before the experiment: 11.27 cc. thiosulphate. After the experiment: 10.47 cc. Difference: 1.80 cc.

14 His paper, Recherches sur la respiration des insectes aquatiques adultes. II. Les Dytiscides. Ann. de Biol. Lacustre, T 4, 1909/11, was not available for me.

${ }^{15}$ I did not yet know the remarkable improvement of this method by Edwin B. Powers, published in the Bull. o. the Ill. State Lab. o. Nat. Hist., vol. 11, May, 1918. 
Experiment B. Animal in the water during $1 \frac{3}{4}$ hours. Before the experiment: $10.18 \mathrm{cc}$. thiosulphate. Afterwards: $9.82 \mathrm{cc}$. Difference: 0.36 cc. thiosulphate.

Unfortunately, I cannot find the volume of the water used in these experiments in my records. Nevertheless, their results prove that some oxygen has disappeared from the water, and this is the only point I wished to state.

5. A glance at the figures given in table 1 for the composition of the air in the animal's store immediately after diving shows us that this air contains an abnormally high percentage of carbon dioxide. The figures of Ege and of Kreuger agree in this respect completely with my own. We may therefore safely conclude that this air is a mixture of expired and atmospheric air, a 'Mischungsluft.'

My first impression of the fact that the first phase of the breathing process is not an 'inspiratorische Schluckbewegung,' but an expiration, was that it would complicate our present knowledge of the problem to such an extent as to make it a chaos of contradicting facts. Certainly, it proves that a great deal of the literature based on this hypothesis is worthless.

It is clear that the only way in which the animal can cause a movement of the droplet in the direction of the distal end of the tube is by reducing the pressure somewhere else, and it is very probable that this reduced pressure will be in its tracheal system and tissues. As the animal's body fluids are incompressible, no other possibility can be realized.

Let us now suppose that in diving the animal takes with it a certain quantity of air, $A$. The oxygen in the air-store is used up as I showed in 1 . The animal gives off carbon dioxide instead of this oxygen, but, as the analyses of three authors show, this $\mathrm{CO}_{2}$ diffuses out very soon into the water. Consequently the volume of the air-store must diminish. Moreover, after some time, as both $\mathrm{CO}_{2}$ and $\mathrm{O}_{2}$ are very low, the partial pressure of nitrogen will be higher than in the water, which is in equilibrium with the air, and nitrogen will diffuse out. All these factors tend to diminish the total volume of the air-store and make it less 
than $A$. And now when the animal comes to the surface it expires! After that it dives again! It is obvious that in this system of reasoning there must be a mistake. In the beginning I tried to find its solution in the process under water and tried to solve the following question: Is the diffusion of oxygen into the bubble sufficient to cover this loss?

This means: Has this oxygen diffusion a biological importance? This has been denied by Ege in his paper cited above. My first hypothesis was that perhaps this author had made a mistake in his complicated calculations or in the determination of the different data used in these calculations. $\mathrm{I}^{16}$ therefore took up the problem in my own way, but my results are the same as those of Ege.

$\alpha$. Bohr has given a formula (used also by Ege) which enables us to find out the quantity of gas which diffuses into or out of a bubble in a certain time. The modification which Ege used is $p_{1}-p_{2}=\frac{M .760}{\gamma . S}$, in which $p_{1}-p_{2}$ is the difference in pressure between bubble and water $(\Delta \mathrm{p}), M$ the change in volume $(\Delta \mathrm{v})$, $\gamma$ the diffusion coefficient of the gas and $S$ the surface through which diffusion takes place.

What I wanted to see was whether $\mathrm{O}_{2}$ would diffuse in faster than $\mathrm{N}_{2}$ diffuses out or not. Now, when we suppose that one diffuses as fast as the other, we have: $\left(\frac{\Delta V}{\Delta \tau}\right)_{\mathrm{O}_{2}}=-\left(\frac{\Delta V}{\Delta \tau}\right)_{\mathrm{N} 2}$.

Substituting Bohr's formula, we have:

$$
\frac{\text { S. } \gamma_{\mathrm{O}_{2}} \cdot \Delta \mathrm{p}_{\mathrm{O}_{2}}}{760}=-\frac{\text { S. } \gamma_{\mathrm{N}_{2}} \cdot \Delta \mathrm{p}_{\mathrm{N}_{2}}}{760} \text {. }
$$

Substituting $\gamma_{\mathrm{O}_{2}}=0.029$ and $\gamma_{\mathrm{N}_{2}}=0.009$ (Ege), we get: $\Delta \mathrm{p}_{\mathrm{O}_{2}} .=-0.31 \Delta \mathrm{p}_{\mathrm{N}_{2}}$. In the water $\mathrm{p}_{\mathrm{N}_{2}}$ is $601 \mathrm{~mm}$. $\mathrm{Hg}$, pressure $\mathrm{O}_{2}$ is $159 \mathrm{~mm}$. Hg. When we take, for instance, the analytical result of our table 1 , analysis 3 , as standard for the composition of the air after the animal has moved for some time in the water, $\Delta \mathrm{p}_{\mathrm{O}_{2}}$ appears to be $-136 \mathrm{~mm}$. Hg. To balance

${ }^{16}$ I am very much obliged to my friend the physical ehemist, Prof. Dr. Allen E. Stearn, who helped me in working this problem and had the kindness to look over these pages. 
this $\Delta \mathrm{p}_{\mathrm{O}_{2}}, \Delta \mathrm{p}_{\mathrm{N}_{2}}$ must have the value of $421 \mathrm{~mm}$. Hg. Actually this value is only $130.8 \mathrm{~mm}$. $\mathrm{Hg}$. This proves that oxygen will diffuse in quicker than $\mathrm{N}_{2}$ diffuses out, even when we do not take into consideration the higher value of $\mathrm{CO}_{2}$ in the bubble.

$\beta$. In this way it has been proved that oxygen really diffuses faster into the bubble than nitrogen diffuses out. It seems even possible that this inflow of oxygen may compensate to a certain extent for the decrease in volume of the bubble.

Another question, however, arises: Will this inflow of oxygen enable the animal to stay under water? In other words: Will the inflow of oxygen compensate the consumption of oxygen of the animal and have in that way a vital biological importance? In that case the only reason for the animal to move upwards would be the lack of nitrogen, though this seems to be a paradox. This question has been denied by Ege, and I completely agree with him, though I believe that it can be demonstrated in a much more simple way.

According to Ege's figures, one Dytiscus consumes in one minute $8 \mathrm{~mm}^{3}$ of oxygen. The quantity which diffuses in can be calculated by means of Bohr's formula: $M=\frac{\gamma \cdot S . \Delta p}{y 60}$. Taking $\mathrm{p}=136 \mathrm{~mm}$., and $\mathrm{s}=10 \mathrm{~mm} .{ }^{2}$ (as Ege did),

$$
\frac{0.029 \times 10 \times 136}{760}=0.52 \mathrm{~mm}^{3}
$$

of oxygen diffusing in. The discrepancy between these two figures is evident.

$\gamma$. In this way we see that the term 'biological importance' which Ege introduced is ambiguous and should be avoided. As far as the oxygen economy is concerned, the oxygen diffusion has no 'biological importance'; that it plays a role in preventing the volume of the bubble from decreasing too quickly has been shown in the given calculations.

$\delta$. The possibility which occurred to me in the beginning that by the inflow of oxygen the volume of the bubble might increase so that the animal would be obliged to move upwards simply to get rid of its superfluous air-in that way the frequent escaping 
of air bubbles from the dorsal space would be explained-is disproved by the fact illustrated in table 1 (decrease of oxygen till about 3 per cent) and by our above-given calculations.

$\epsilon$. Concluding these theoretical considerations, we may state: 1) that from the statistical standpoint a state of sliding equilibrium between bubble and water will be reached after a while in which $\mathrm{O}_{2}$ diffuses in and compensates the outflow of $\mathrm{N}_{2}$ (and $\mathrm{CO}_{2}$ ?) ; 2) taking into consideration the animal's consumption of oxygen, we can see that this inflow has no real 'biological importance' in the sense in which Ege used this expression.

This attempt at an explanation revealed some interesting facts, but does not give the solution of our problem. It appears that the problem cannot be solved by applying physical chemistry to the processes which happen during the animal's stay in the water. So we are logically obliged to find its solution in the process of breathing itself and in doing so we must keep in mind: 1) that the animal expels the droplet of petroleum-this proves that a vacuum must be made somewhere as shown above; 2 ) that the air in the dorsal space in the moment of diving is a mixture of atmospheric and tracheal air (see 5). I believe that these facts enable us to give only one explanation of the whole mechanism as follows (though it took me a long time to find it-it is something like the egg of Columbus and extremely simple . . . . after one has realized it):

As soon as the animal has opened its abdominal cleft, it moves its back slowly downwards. Consequently, the air in the stigmata is compressed just a little bit and flows out, partly through the dorsal, partly through the terminal stigmata. In that way no movement of the droplet can be expected because no vacuum nor noticeable compression is made. In this connection it is remarkable that in several experiments I could observe that the droplet continued its backward movement for a few seconds after the cleft had made communication between the dorsal space and the atmosphere. This may perhaps be an indication in favor of my hypothesis. The only effect of the postulated movement is that the tracheal air is expelled from the tracheae into the dorsal space and perhaps into the free air (in the latter case 
a compensatory inflow of air from the atmosphere into the dorsal space is to be expected). Most probably the period called A in our description corresponds to this movement. Now the back of the animal is raised again. Through the stigmata the air sucks into the newly formed vacuum, but it is not able to penetrate soon enough into the tracheae to compensate the vacuum. Consequently, we must expect the droplet to move into the direction of the distal end of the tube, as in fact was observed. Part of the air in the dorsal space is expelled, and as soon as the back has returned into its position of equilibrium the animal dives (this position will most probably depend on the hydrostatic function of the air-store which has been emphasized by Brocher (p. 344) and Wesenberg-Lund ${ }^{17}$ ). From that moment the movement of the droplet must go in the opposite direction, which is in fact observed. Never could I notice any exception to this postulate. Now here is another feature in favor of my conception of the whole process. When the backward movement of the droplet was due only to the diffusion of the expired $\mathrm{CO}_{2}$ into the water, we would expect it to be very slow-in the case the oxygen inflow compensates the outflow of $\mathrm{N}_{2}$ and that of $\mathrm{CO}_{2}$ completely the droplet would even stay where it was. This is, however, not the case: the droplet goes back rather speedily though not as speedily as during the expiration (observation $\mathrm{D}$ and fig. 2). This must be due to the gradual filling up of the vacuum by the air which sucks through the stigmata! After a while this vacuum must be filled up, and now we may expect the droplet to move much more slowly, perhaps even to come to a standstill. This was actually observed (observation D).

In this way no difficulty can be encountered any longer in the explanation of the movements, so far as I can see.

Some more experiments have been made to study the degree of emancipation of Dytiscus from its original medium - the air.

I had the animal respire in different atmospheres while, moreover, the gas content of the water was varied. In this way I hoped to get an impression of the relative importance of these

${ }_{17}$ Wesenberg-Lund. Biologische Studien über Dytiscus. Internat. Revue d. Hydrobiologie und Hydrographie. Biol. Suppl., 5 Sér. 1912, p. 89. 
two factors. In each experiment the time spent at the surface was determined by means of a stop-watch and tabulated. The experiments lasted half an hour; in the table I also indicated the ten-minute periods.

The experiments were:

TABLE 3

Experiment 1. Dytiscus $\circlearrowleft$. Water normal.

$7.3 ; 10 \mathrm{~min} . ; 35 ; 20 \mathrm{~min} . ; 1.2$. Total 48 .

Experiment 2. Dytiscus هึ. Water boiled.

5.2.32.150.7.5.15.7.47; $10 \mathrm{~min}$; 7.5.3.3.7.7.105.6.5.13; $20 \mathrm{~min}$; 1.1.1.1.18.9.1. 160.10.63. Total $270+162+264=696$.

Experiment 3. Dytiscus 07 . Water normal. $\mathrm{CO}_{2}$ atmosphere.

In the first $10 \mathrm{~min}$. the animal stayed about 100 sec. under water, after that it was about continuously at the surface.

Experiment 4. Dytiscus 0 ?. Water normal. $\mathrm{H}_{2}$ atmosphere.

20.2.1.2.60.5.34.40.55.50.3.25; $10 \mathrm{~min}$; 50.4.1.15.150.230.5.10.120.5.10.120; 20 min.; 70.30.145.31.65.80.150. Total $297+585+570=1452$.

The animal gave the impression that it was not able to dive. Perhaps the hydrogen gives a marked decrease in specific gravity so that it is made very difficult for it to dive.

Experiment 5. Dytiscus $\sigma^{7}$. Water boiled, allowed to cool and then saturated with carbon dioxide. Air normal.

2.2.6.2.5.1.1.16.1.2.1.1.1.4.7; 5 min.; 5.1.29.1.1.2.1.1.1.4.1.12; $10 \mathrm{~min}$; 2.71.4. 1.60; 15 min.; 55.1.3; 20 min. ; 2.28.32; 25 min.; 14.3.5.4.2.4.21.4. Total $111+197+119=427$.

These experiments show clearly that not only the composition of the atmosphere, but also the gas content of the water has a noticeable influence on the animal's behavior, as far as breathing is concerned. When we compare, for instance, experiments 1 and 2 , we see a remarkable increase in the number of times in which the animal goes to the surface and in the time spent there. This is only due to the fact that in one case the gases have been expelled from the water so that the air in the air-store must diffuse out. Very remarkable in this connection is the fact that less time is spent at the surface when the water after having been boiled and allowed to cool is saturated with $\mathrm{CO}_{2}$ (exp. 5). In that way $\mathrm{CO}_{2}$ cannot diffuse out and decrease in volume is at a much slower rate.

In the second place, these experiments show once more that the importance of this gas diffusion has not been realized sufficiently 
by most students of this problem. Once more we can see that it really has a 'biological importance,' though not in the sense in which Ege has used this expression.

Much more important than the air content of the water is the composition of the atmosphere. A glance at experiments 3 and 4 shows us immediately how in case of substituting some other gas for the normal air the animal almost continuously hangs at the surface. $\mathrm{CO}_{2}$ has a stronger influence than $\mathrm{H}_{2}$, perhaps because it stimulates in some way the centers for breathing.

In this way we are able to demonstrate that Dytiscus, though it changed its medium, is still dependent of its original milieu and that changes in this initial environment affect it much more than changes in the water. This fact is also nicely illustrated by the observation of Plateau, ${ }^{18}$ that some 'land' beetles could endure immersion in the water without contact with the air longer than the water-beetle Dytiscus. Oryctes nasicornis, for instance, could on the average stay ninety-six hours under water, Dytiscus only sixty-five hours. Nevertheless, we can mention certain facts, phenomena which without doubt prove a certain adaptation to the new medium. Among these could be mentioned anatomical features, as the structure of the legs, the backward movement of the stigmata, the establishment of the dorsal air-chamber, and the strueture of the cleft, but also physiological peculiarities, such as the whole breathing mechanism, as it has been analyzed in the present paper. The facts that the beetle is in some way influenced by the gas content of the water, that the oxygen inflow into the air-store is necessary in order to prevent it from decreasing in volume too rapidly, show that the animal has established some relations, some 'Wechselbeziehungen' with the water. These phenomena we might call phenomena of adaptation.

18 F. Plateau. Recherches physicochémiques sur les articulés aquatiques. 2me partie. Bull. Acad. Roy. Beg., 4lme Ann. 2me Sér., T. 34, p. 263. 


\section{SUMMARY}

With a new apparatus the mechanism of breathing of Dytiscus marginalis L. is studied. The movements of a droplet of petroleum are observed when the animal is allowed to breathe in a space which is closed by this droplet. It appears that the first observable movement is an expiration, which fact is in contradiction with previous statements of other authors. A theory is given to explain this fact and in several ways the verification of this theory is tried. With a new apparatus the air is studied after the animal is allowed to breathe in it for some time. The fact reported by Ege and Kreuger that the $\mathrm{O}_{2}$ in the air-store is consumed during the animal's stay under water was proved again. The biological importance of the oxygen diffusion into the air-store is discussed from the physico-chemical standpoint and treated mathematically.

Finally, the relative importance of the gases in the water and in the air for the animal's behavior is studied. It appears that though the animal has become emancipated to a certain extent from its original environment, it is still more dependent on the air than on the gas content of the water.

Thanks are due to Prof. Dr. Withrow Morse who tried to make my English readable even for the English reader - and I trust he succeeded-and corrected the many mistakes.

Morgantown, W. VA., U. S. A., January 6, 1921 